\title{
Diversidad Religiosa en los textos escolares de CentroaméricA
}

\author{
Religious Diversity in the Text Books of Central America
}

\author{
Gabriel Ascencio-Franco
}

\begin{abstract}
Resumen: Enel presenteescrito se explora la invisibilización de la diversidad religiosa entextose imágenes de los libros escolares de ciencias sociales para la educación básica en los países de Centroamérica, la cual es producto de la decimonónica narrativa en torno a la nación homogénea - una religión, una lengua, una cultura - que sigue dominando a pesar de la proliferación del discurso multicultural desde el quinto centenario del arribo europeo a América y la transición hacia regímenes más democráticos en las últimas décadas, que propugnarían una convivencia intercultural basada en la lealtad cívica o el patriotismo constitucional opuesto a nacionalismos homogeneizantes.
\end{abstract}

Palabras clave: civismo, patriotismo, multiculturalidad, interculturalidad, religión, libros de texto.

Abstract:Drawing upon images and texts, the article explores how religious diversity is erased in elementary school social science textbooks in Central America. It argues the politics of erasure is a product of nineteenth century narratives of a homogenous nation - with a single religion, language and culture. These narratives persist despite the emergence of multicultural discourses in the context of the fifth century of European colonization of the Americas and the transition towards more democratic regimes in the last decades that would promote intercultural relationships based on civic loyalty or constitutional patriotism opposed to homogenizing nationalisms.

Keywords: civility, patriotism, multiculturalism, intercultural relationships, religion, textbooks.

Gabriel Ascencio Franco, doctor en Antropología por la Universidad Nacional Autónoma de México. Investigador en el Centro de Investigaciones Multidisciplinarias sobre Chiapas y la Frontera Sur de la UNAM (CIMSUR-UNAM), México. Temas de especialización: antropología de la educación. Correo electrónico: gafranco@unam.mx.

Enviado a dictamen: 20 de enero de 2015. Aprobación: 17 de abril de 2015.

Revisiones: 2. 


\section{Introducción}

L a creación de un cosmopolitismo cívico que podría generar lealtad patriótica de raíz republicana, contrapuesta a la étnica o cultural defendida por el nacionalismo, exige construir una identidad posnacional fincada en los principios universalistas del Estado de derecho y la democracia que ayuda a pensar en una educación constitucional de la ciudadanía (Rosales, 2000b: 133).

La distinción analítica entre nacionalismo y patriotismo permite ver que el encuentro y antagonismo entrelasnaciones en la formación de los Estados desmiente el desiderátum nacionalista de correspondencia entre nación y Estado. Además, permite ver que "la cohesión cívica de las comunidades políticas, integradas habitualmente por una pluralidad de comunidades nacionales, se produce como resultado de un complejo proceso de articulación cívica de la diferencia” (Rosales, 2000a: 127).

El patriotismo constitucional representa una alternativa razonable de identidad política: supranacional y al mismo tiempo compatible con una pluralidad de identidades nacionales. Patriotismo y nacionalismo no son sinónimos, porque adhesión al propio Estado es patriotismo, y adhesión al propio pueblo es nacionalismo (Rosales, 2000b: 138 y 148).

En síntesis, la convivencia intercultural es posible cuando viene acompañada de la construcción de una identidad basada en el patriotismo constitucional, alejada de nacionalismos homogeneizantes. Por eso, encuentro importante analizar los contenidos de los libros escolares sobre la diversidad religiosa afincado en la certeza de que "el libro de texto puede ser parcialmente liberador", aunque:

[...] a menudo el texto se convierte en otro aspecto de los sistemas de control [...] Poco es lo que queda a la elección del maestro a medida que el Estado invade cada vez más los tipos de conocimiento que se debe enseñar, los productos y metas finales de la enseñanza y los modos de lograrlos (Apple, 1986: 87-88).
Desde la misma Revolución francesa de 1789, el manual escolar recibía de parte del Estado un lugar central, se estimaba "que el libro escolar, conjuntamente con las fiestas populares, era la herramienta mejor adaptada y más potente para la difusión de las nuevas ideas [...] el Informe y Proyectos de Ley sobre los libros elementales presentado a la Convención en 1793" declaraba a los libros elementales como columna, sostén de la educación" (Carbone, 2003: 15).

Sin duda, "El libro de texto tiene más presencia que otros libros escolares en la memoria colectiva; por eso es probable que los sentimientos o emociones evocados no sean tan superficiales como para relegarlos al olvido" (Carbone, 2003: 13).

[...] la imagen que tenemos de otros pueblos, y hasta de nosotros mismos, está asociada a la historia tal como se nos contó cuando éramos niños. Ella deja su huella en nosotros para toda la existencia [...] La historia que se cuenta a los niños, o a los adultos, permite a la vez conocer la identidad de una sociedad y el estatus de ésta a través del tiempo (Ferro, 2007: 19 y 21).

El libro escolar es un espejo de la sociedad que lo produce, un escenario material en el que se representan los valores y las actitudes, los estereotipos y las ideologías que caracterizan la mentalidad colectiva, es decir, el imaginario de cada época (Escolano, 1997: 15).

Dada la centralidad de los manuales escolares como proyectos de Estado y reflejo de la mentalidad colectiva, según se traduce de las citas previas, y aunado a la evolución de los gobiernos centroamericanos hacia regímenes con principios democráticos promotores de la conservación ambiental y del respeto de la diversidad cultural y los derechos humanos en las últimas tres décadas, me pregunto por la presencia o ausencia del respeto y aprecio de la diversidad religiosa que, aunque antigua en la región, ha ampliado su espectro en el último medio siglo en los países del istmo centroamericano. Esta pregunta es pertinente 
para valorar en qué medida los textos escolares son fieles al discurso de la interculturalidad adoptado en los programas educativos oficiales y si, por lo tanto, resultan pertinentes para la generación de una identidad basada en el patriotismo constitucional.

\section{Pluralidad religiosa sin pluralismo}

La rápida expansión de nuevas Iglesias en las últimas décadas en todo el istmo centroamericano es bien conocida. Desde principios del XX llegaron bautistas, presbiterianos y metodistas, ${ }^{1}$ pero sin duda acaeció un cambio manifiesto en la segunda mitad del siglo. ${ }^{2}$ Sin embargo, la diversidad es más antigua porque, por ejemplo, los anglicanos llegaron en el siglo XVII con el proyecto inglés de colonización de la Mosquitia y de toda la costa del Caribe. ${ }^{3}$ Más tarde, a mediados del XIX, los misioneros moravos se establecieron entre los misquitos y convirtieron masivamente tanto a los nicaragüenses como a los hondureños, hasta volverse un rasgo de la etnicidad regional y un parche temprano, no católico, en toda Latinoamérica (Tilleman, 2004).

En la actualidad la diversidad es mucho más extensa. Las denominaciones se cuentan por centenas y las iglesias por miles. En el triángulo del norte, formado por Guatemala, Honduras y El Salvador, la población protestante o evangélica representa alrededor de un tercio, mientras que en los otros países, Nicaragua, Costa Rica y Panamá, representa entre una quinta y una cuarta parte del total ${ }^{4}$ (ver cuadro l).

También abonan a la diversidad religiosa de Centroamérica la inmigración china, la antillana y la alemana que acudieron a trabajar en la construcción del Canal de Panamá, el desarrollo de la cafeticultura y las explotaciones bananeras entre los siglos XIX y $\mathrm{XX}$, además de la llegada de colonos judíos, turcos $y$ de otras nacionalidades, que formaron colonias influyentes y distinguidas. Sin embargo, el predominio de la religión católica permanece y marca los sistemas educativos hasta el presente a pesar de la diversidad que se capta a simple vista.

En 2007, durante una estancia en Honduras, pude ver por televisión, en una cadena nacional, al presidente
Manuel Zelaya pronunciando un discurso lleno de invocaciones religiosas. El motivo del discurso era otorgar la medalla de honor al obispo de Tegucigalpa por su cabildeo ante instancias multilaterales para que el país pudiera acceder a ayuda internacional por la situación de extrema pobreza de la población. El obispo, por el contrario, respondió con un discurso político, sin tintes religiosos.

En un recorrido por Centroamérica para adquirir los libros escolares vigentes en cada país durante el año 2009, recogí testimonios aislados que dan cuenta de la invisibilización de la diversidad religiosa y la supremacía de la religión católica. Por ejemplo, una profesora de la Universidad Nacional me aseguró que en Nicaragua el currículo no contempla clases de religión, pero que los maestros que quieren, rezan, y cuando hablan de valores, creen que se trata de valores cristianos. En cambio, un taxista evangélico, con hijos católicos y casado con una católica desde hacía 27 años, me contó que en las escuelas públicas se imparten clases de catolicismo, principalmente en los tres primeros años, y que los niños tienen que presentar examen aunque no sean católicos.

En Managua, en ocasión de celebrarse el trigésimo aniversario del triunfo sandinista, grandes espectaculares mostraban al presidente Daniel Ortega diciendo: "cumplir con el pueblo es cumplir con dios", mientras de los postes del alumbrado público colgaban pendones invitando a una gran reunión con el líder evangélico centroamericano del momento.

Un taxista tico me contó que se imparten clases de religión en las escuelas del gobierno y que los padres no católicos remiten una carta para que se exima a sus hijos de tomarlas. Los que tienen dinero, envían a sus niños y jóvenes a colegios y universidades evangélicas, pentecostales o anglicanas. Dos destacadas antropólogas, profesoras de la Universidad de Costa Rica, me comentaron que tenían problemas con los alumnos testigos de Jehová y recordaban cómo, cuando ellas estaban en el colegio hacía ya medio siglo, tenían compañeras judías que, a la hora de rezar o de la clase de religión, se salían sin provocar problema alguno, y realizaban otras actividades durante ese tiempo. Me 
aseguraron que, en su país, el obispo católico tenía poder incluso para dar el visto bueno al nombramiento de algunos funcionarios del gabinete presidencial.

En Panamá, el decano de la Facultad de Educación me confirmó que en la Universidad Autónoma de Chiriquí, una universidad pública, tenían capellán universitario, mientras que un taxista bautista me contó que las clases de religión católica estaban vigentes en la escuela pública porque era una materia oficial, pero que había escuelas privadas de otras religiones. Él no tenía dinero para mandar a estos establecimientos a sus hijos, pero en su casa les aseguraba que las cosas no eran como les decían en la escuela y les recomendaba que no hicieran caso a lo que escuchaban en las clases de catolicismo. Un maestro me contó que incorporaba contenidos relacionados con los derechos humanos en la clase de religión.

¿En qué medida los libros de ciencias sociales son otro ejemplo de estas estampas?, ¿cómo promueven o contradicen el respeto y aprecio de la diversidad en países como Panamá y Costa Rica, donde se enseña religión católica en las escuelas públicas y hay una religión oficial, aunque sus constituciones tutelan la libertad de cultos?, ¿cómo son los libros de Nicaragua y Honduras, donde sus presidentes invocan a dios en sus discursos?

\section{Diversidad religiosa en los libros de Ciencias Sociales}

Los contenidos de los libros escolares de Ciencias Sociales de todos los países van dosificando sus contenidos del primero al sexto grado según una escala que lleva de lo local a lo continental y mundial. Dicha escala arranca en primero desde la familia y la localidad; le sigue el estudio del distrito o municipio y del ayuntamiento, la provincia o departamento y la dirección regional, el país y el gobierno nacional, Centroamérica y las políticas de integración regional, hasta terminar con el continente y los organismos multilaterales en los casos de Panamá, Costa Rica y El Salvador, y el mundo y las multilaterales en los ejemplos de Guatemala, Honduras y Nicaragua.
En general, los libros están compuestos por cuatro unidades en las que se pueden distinguir las disciplinas tradicionales: geografía, civismo e historia.

\section{Panamá}

Los seis volúmenes de Panamá están compuestos por cuatro unidades con un número variable de temas, secciones y recuadros. ${ }^{5}$ Las unidades son: "Naturaleza y sociedad", "Interacción con el medio", "Convivencia con el medio" y "Acontecer histórico". Los contenidos que interesan para el tema religioso aparecen especialmente en las dos últimas. En la tercera unidad se habla de deberes, derechos, población y organización del Estado, y en la cuarta de diversidad cultural, historia política y símbolos patrios.

En el libro de primero se presenta el cromo de una procesión encabezada por un sacerdote católico ataviado con el atuendo ceremonial y portando los símbolos centrales e inconfundibles de su confesión. Allí se pregunta a los niños en qué lugares han visto esas actividades, si participan en ellas y por las actividades religiosas que celebran sus familiares. Además, en un recuadro inmediato se indica que:

Las comunidades se diferencian por su población y por las actividades sociales, culturales y económicas que practican. Toda comunidad construye su historia desde que se funda. Conforme pasa el tiempo la comunidad crece. Los habitantes adquieren tradiciones y costumbres del lugar, y también festejan el día del santo patrón de la iglesia a la que pertenecen o el santo de la comunidad (Santillana pa. $1^{\circ}$ g. 2006: 169).

En este párrafo se asume la catolicidad, que celebra a sus santos con toda claridad ignorando la diversidad religiosa existente. ${ }^{?}$

El libro de segundo, en relación con los deberes y derechos, define a los ciudadanos como los panameños mayores de 18 años, "sin importar su sexo, creencias [...]". También se dice que cada persona cuenta con característicasfísicas particulares y diferencias culturales, 
como sus creencias. Se describen los contrastes físicos, pero no las creencias y, cuando se habla del traje típico, se declara su uso en fiestas patrias, patronales y carnaval. Se hace énfasis en la diferencia entre comunidades por la fiesta patronal y se vuelve a la foto del sacerdote en procesión, ahora éste en primer plano; en cambio, no se menciona ninguna religiosidad distinta (Santillana pa. $2^{\circ}$ g. 2006: 109, 117, 151, 167 y 169).

El volumen de tercer grado vuelve a la fiesta patronal y a la Semana Santa; se destacan idioma y religión como aportes de la conquista española, así como la evangelización y las celebraciones religiosas (Santillana pa. $3^{\circ}$ g. 2006: 11, 125, 127, 131, 142, 144).

El texto de cuarto año deja descansar de santos a los niños panameños. Hay una mención de la religión cuando se plantea que el ideal de Simón Bolívar era la creación de una gran nación, con una religión y una lengua en un amplio territorio, lo que hubiera sido buen momento para mostrar la lista de las adscripciones religiosas del presente (Santillana pa.4ํㅡ. 2006: 168).

El libro de quinto, al tratar de los derechos humanos menciona, entre otras libertades, la libertad religiosa, y las diferencias religiosas como uno de los elementos que provoca discriminación. Al referirse a la diversidad cultural, se plantea la imposición del idioma por parte de los españoles y "el establecimiento de la religión católica, que hoy es oficial”. También se recuerda la inmigración de la segunda mitad del XIX y primera del XX estimulada, entre otros factores, por la construcción del ferrocarril transístmico, el Canal de Panamá y la expansión de las plantaciones bananeras: los hebreos y griegos establecieron colonias e "intentan mantener sus tradiciones por medio de sus iglesias, festivales [...]". Además, se menciona a los negros antillanos, unos originarios de posesiones francesas y otros de colonias inglesas, con religión anglicana, y, para completar el panorama de la diversidad cultural, se recuerda a los inmigrantes norteamericanos, chinos y originarios de la India, pero no se hace ninguna referencia a sus prácticas religiosas (Santillana pa. $5^{\circ} \mathrm{g}$. 2006: 92, 101, 132, 133, 134, 135, 136).

El volumen de sexto grado destaca la importancia del respeto a los valores éticos, morales y religiosos para las relaciones interculturales, y el derecho del individuo a la propiedad, a la libre expresión de pensamiento, y a la libertad de religión y de enseñanza. Como se dedica en términos de escala al continente americano, enuncia la diversidad religiosa, pero no hace referencia a las Iglesias cristianas históricas ni a las de aparición reciente (Santillana pa. $6^{\circ}$ g. 2006: 103, 107, 119, 168).

En cambio, para explicar los antecedentes del descubrimiento de América, hay una referencia a la reconquista de España y a la expulsión de los musulmanes. Este tema se menciona en un recuadro de una manera que no ayuda a entender el asunto religioso: "Se les llama musulmanes a los seguidores de la religión llamada Islam. Los musulmanes se extendieron hacia África y Europa para expandir su religión. En España les llamaban moros" (Santillana pa.6으. 2006: 164).

En ninguno de los objetivos a lo largo de los seis volúmenes se llama la atención acerca de la diversidad religiosa. En los contenidos, más bien se asume la catolicidad como universal, derivada de la historia colonial, omnipresente en la invocación de las fiestas de los santos patrones de la actualidad. Las referencias a esta religión están mal equilibradas respecto a las escasas menciones de otras confesiones, y no se explican las diferencias de una manera mínimamente sustantiva. Por tanto, aunque el respeto y aprecio a la diversidad aparecen en estos textos mediante la invocación de la diversidad cultural, sólo se enuncian algunas adscripciones religiosas diferentes, sin describir sus prácticas, sus contrastes y la diferenciación de credos o la interrelación entre sus feligresías: ¿cómo apreciar y respetar lo que se desconoce?

\section{Costa Rica}

Los libros escolares de Costa Rica de la editorial Eduvisión, a diferencia de los editados por Santillana, manifiestan una clara tendencia confesional. El texto de primer grado invoca la oración del “iAve María!" en una leyenda popular. En una lección sobre la familia se agradece a Dios por tenerla y por disfrutar del derecho a comer. Más adelante, se presenta como norma de decoro agradecer a Dios por lo que se va a recibir al 
sentarse a la mesa. Al describir el entorno del niño, el barrio, se nombra la iglesia, el recinto religioso de los católicos, aunque en la ilustración siguiente sobre el barrio se rotula un edificio con una cruz en lo alto con la leyenda "Iglesias de diferentes religiones". Sin embargo más adelante, cuando se habla del distrito, se expresan en singular las palabras escuela, iglesia, parque y centro de salud, y en plural las palabras bancos y locales comerciales; además, para ilustrar la referencia a la iglesia, en el conjunto de imágenes del distrito aparece la foto de un templo católico (Eduvisión cr..$^{\mathrm{0}} \mathrm{g}$. 2007: 4, $33,34,37,60,96,98,150,158)$.

El libro de segundo invoca a la virgen de Los Ángeles y da gracias a Dios por los recursos naturales de los que gozamos. Ubica en Cartago la basílica de Nuestra Señora de los Ángeles, patrona de Costa Rica, y en la retroalimentación pide a los estudiantes mencionar dónde se ubica. En el libro de tercero se repite la referencia a la patrona del país (Eduvisión cr.2 ${ }^{\circ}$ g. 2007: 54, 86, 131, 135; Eduvisión cr. $3^{\circ}$ g. 2007: 70).

El libro de cuarto año explica periodos históricos y ubica el surgimiento de las religiones:

La Edad Antigua simboliza el surgimiento de las religiones. Confucio en China, Buda en la India trazaron las reglas de oro de la conducta humana y dieron al mundo códigos morales que reclamaban la paz, la justicia y el amor. En el Medio Oriente, en la hoy convulsionada Palestina, Jesús de Nazaret dio al mundo su doctrina, forjadora de santos y de mártires, doctrina que sella con su propia sangre y que conmueve al mundo, de manera que el tiempo llega a medirse antes de Cristo o después de él (Eduvisión cr.4ºg. 2007: 154, cursivas nuestras).

Esta narrativa confesional de énfasis católico ignora que musulmanes y chinos tienen sus propios calendarios. En otro apartado que aparece bajo el rotulo "Pensamiento crítico", se afirma que "Dios expresó en el sexto mandamiento iNo matarás!", abunda en que en muchos países se aplica la pena de muerte y se pregunta si los humanos tenemos derecho a quitarle la vida a otro como castigo (Eduvisión cr. $4^{\mathrm{O}} \mathrm{g}$. 2007: 194). Usar ejemplos religiosos aun en leyendas populares es congruente en Costa Rica, en donde la religión católica es oficial y, por tanto, prácticamente no existe ninguna referencia a la diversidad religiosa. Sin embargo, la editorial Santillana, al contrario de Eduvisión, evita hacer referencias a temas o lugares religiosos, a diferencia de los panameños de Santillana. ${ }^{8}$

\section{Nicaragua}

En Nicaragua hay libros de Ciencias Sociales sólo del tercero al sexto grado. El de tercero, publicado por la editorial San Jerónimo, no esconde cierta diversidad, pero apenas refiere la existencia de otros credos en la zona atlántica: "Sus habitantes originarios profesan la religión anglicana y la morava. Los mestizos en su mayoría son católicos". En cambio, abunda en la catolicidad como folclor, lo que apuntala la identidad nacional monoétnica en torno a una religión, una lengua y una cultura:

Las festividades de "La Purísima" tienen un especial significado porque en la Basílica de la Inmaculada Concepción de El Viejo se celebra "La lavada de la plata" que es una actividad anterior a "La gritería" [...] El 6 de diciembre, los promesantes lavan los adornos del altar y todos los objetos de plata que tiene el templo [...] Ese día es la solemne "bajada" de La Virgen. La colocan en un altar al alcance del público. La gente hace largas filas para adornarla con mucha devoción, después de la misa que se celebra con toda pompa [...] El folklore chinandegano es muy rico en cuentos, leyendas, poesías infantiles, en fin, todo aquello que se transmite a través de la historia que no está escrita, pero permanece en las costumbres del pueblo [...] También se manifiesta en danzas y cantos durante las procesiones. Una de ellas, es la de San Pascual Bailón el día 17 de mayo [...] León es la cuna de "La Gritería", nuestra fiesta católica nacional, que tú conoces bien (San Jerónimo ni. $3^{\circ} \mathrm{g}$. 2006: 33, 34, 38, 75).

Este libro de Nicaragua, alejado del respeto a las diferencias, llama ídolos a las estatuillas encontradas 
por los arqueólogos. En este sentido, por ejemplo, se menciona que "[los historiadores piensan que] las islas de Zapatera y Ometepe eran un 'santuario destinado al culto' [...] porque se han encontrado grandes cantidades de ídolos en esas islas (San Jerónimo ni.3ํ․ 2006: 123).

Al referirse a la escuela, también se hace proselitismo católico y se omite la existencia de centros escolares sostenidos por denominaciones religiosas diferentes a la católica:

La educación religiosa es también una herencia de la época colonial. Junto a los templos se construían las escuelas parroquiales donde se enseñaba la región católica. Esto sigue siendo una costumbre. En la actualidad, al lado de muchos templos hay escuelas de enseñanza primaria y talleres de artes y oficios (San Jerónimo ni. $3^{\circ} \mathrm{g}$. 2006: 153).

Nada se dice de las prácticas escolares de otras confesiones aún más acendradas, como entre los que hacen de la lectura de la Biblia el eje de su religiosidad. El libro de cuarto repite la enunciación de la diversidad religiosa limitada:

La región del Atlántico es la menos poblada del país. Su población está compuesta de grupos étnicos diferentes que hablan idiomas distintos y tienen otras costumbres que enriquecen nuestra cultura... Practican varias religiones entre ellas la anglicana, la morava, la evangélica y la católica. Sus templos tienen formas de construcción muy especial (San Jerónimo ni.4으. 2006: 88, 89)

\section{Y recapitulando enfatiza:}

[...] ya estudiaste que con la colonización española se produjo también un mestizaje cultural o mezcla de culturas. Por eso hablamos español, practicamos el catolicismo y tenemos costumbres parecidas a las costumbres de los españoles. También debes recordar la influencia de los ingleses en la Costa Atlántica donde muchos grupos étnicos hablan inglés y practican religiones como la anglicana, la Morava, la
Bautista, la presbiterana, etc. Nuestra Constitución Política expresa que en Nicaragua "toda persona tiene derecho a la libertad de conciencia”. Hay libertad de cultos. La educación es laica. Por eso en las escuelas estatales no se enseña región alguna (San Jerónimo ni. $4^{\circ}$ g. 2006: 174).

El libro de quinto, dedicado a Centroamérica, presenta datos estadísticos por país y en él llama la atención la insistencia en los rasgos comunes mestizos:

Muchas de nuestras maneras de ser tienen su origen en las formas de vida de nuestros antepasados: la alimentación de nuestros pueblos sigue basándose en productos derivados del maíz, el tiste sigue siendo una bebida popular; seguimos cultivando cacao, frijoles algodón, etc., tenemos utensilios de barro para diferentes propósitos. Desde el punto de vista religioso seguimos haciendo bailes típicos con vistosos trajes tradicionales en nuestras procesiones (San Jerónimo ni. $5^{\circ} \mathrm{g}$, 2006: 85).

El libro de sexto da importancia al nacimiento y expansión del cristianismo, y en ese marco enfatiza la catolicidad, aunque registra a otras Iglesias cristianas:

La gran mayoría de los nicaragüenses son católicos y protestantes (evangelistas, moravos, metodistas) y muchas otras denominaciones que creen que Cristo es el hijo de dios y el mesías prometido en el Antiguo Testamento de la Biblia [...] La religión cristiana (católica) fue traída y difundida en nuestro país por los misioneros (sacerdotes) que vinieron con los conquistadores españoles a partir del año 1520 (San Jerónimo ni. $6^{\circ}$ g. 2006: 141).

Igual pasa con los libros editados por Hispamer. El de quinto, dedicado a Centroamérica, enfatiza los rasgos compartidos. Allí se afirma:

El cristianismo fue la religión de toda la población. En las prácticas religiosas se conservaron rasgos indígenas. En las iglesias, los instrumentos musicales indígenas como la chirimía y el tambor acompañaban 
a los cantores. La marimba de origen africano, pasó a ser un instrumento musical indígena (Hispamer ni. $5^{\circ}$ g. 2007: 118).

En el de sexto, dedicado al mundo, se advierte la existencia de otras grandes religiones históricas, aunque sólo se enuncian:

Además de su origen étnico, la población mundial se caracteriza por la diversidad de sus lenguas y religiones [...] En el ámbito religioso destacan varias líneas, los que siguen las enseñanzas de Jesucristo (cristianismo), o de Mahoma (islamismo) o de Siddhartha Gautama o Buda (budismo), también destacan otras religiones, como judaísmo, taoísmo, sintoísmo y confucionismo (Hispamer ni.6ㅇ. 2007: 181).

\section{El Salvador}

Los libros de El Salvador del Ministerio de Educación también presentan la religión católica como costumbre y patrimonio. Así, en una sección que se repite lección por lección en todos los grados, denominada "Postales de viaje", se invita a visitar el Santuario de Esquipulas, la iglesia colonial de Panchimalco y la catedral de San Vicente (Mined sl.1으. 2008: 36, 42, 136).

Se informa que:

Nuestros antepasados eran politeístas es decir que creían en muchos dioses: los dioses que adoraban los pipiles eran muy semejantes a los de otros pueblos nahuas de Mesoamérica, entre ellos: Tláloc: dios de la lluvia; Xipec Totec: dios de la agricultura y del maíz y Quetzalcóatl o Kukulcán: serpiente emplumada, dios dador del conocimiento y la civilización. [Además que] la vida estaba bajo la protección de un animal, a esto se llamaba nahualismo (Mined sl.4ํ․ 2009: 129).

Asimismo, se comenta que:

Una cofradía es una asociación religiosa traída por los españoles y adoptada por los indígenas, formada por un mayordomo, una mayordoma o capitana, tres priostes (órgano consultivo e intermediarios para llevar a cabo la ejecución de tareas encaminadas a la organización de la fiesta). Hoy en día, se realiza por lo general en torno a una advocación de Cristo, la Virgen o un Santo, un momento de la pasión o de una reliquia: conlleva entre otras cosas, procesiones coloridas, reparto de bebidas y comidas típicas (Mined sl.6ำ. 2009: 50).

En estos libros del Ministerio de Educación, cuando se trata de instituciones de la Iglesia católica se describe su dinámica y se profundiza en su significado y en su organización, pero no se hace lo mismo en relación con otras Iglesias. En los libros de Santillana el planteamiento no es muy diferente. Bajo el rótulo "nuestras costumbres" o "costumbres de mi tierra", se destacan las fiestas patronales en los libros de tercero y quinto:

Entre las tradiciones principales están las fiestas patronales que se realizan en honor del santo patrón del lugar o del país. Todas las comunidades, celebran su fiesta patronal [...] Algunas tradiciones empezaron con la llegada de los españoles. Otras son de origen indígena y con el paso del tiempo se mezclaron con las de los conquistadores hasta llegar a ser como las conocemos hoy (Santillana sl.3ํํ․ 2008: 156).

En Centroamérica también se mantienen importantes costumbres y tradiciones. Son ejemplos: las celebraciones para conmemorar los días de los santos locales y otros eventos religiosos. La marimba es el instrumento musical más popular en Guatemala y Nicaragua. Otros instrumentos importantes son la guitarra, la chirimía y el tun (Santillana sl.5ำ. 2007: 45).

En el libro de sexto año, también de la editorial Santillana, se habla del multiculturalismo y del multilingüismo, pero se enfatiza y celebra, más que la diversidad, lo que es común:

La procedencia multicultural, en el caso de los americanos, es un elemento que determina que la 
población sea multilingüe. En el continente se habla castellano, inglés, portugués, francés y una variedad de lenguas indígenas. También se hablan, en menor medida, otras lenguas europeas y asiáticas [...] Por sobre toda esa variedad, existen creencias, costumbres y valores compartidos por amplios sectores de la población americana, que trascienden el ámbito de las fronteras nacionales. Por ejemplo, la práctica de la religión cristiana, el uso del idioma castellano y la pasión por el futbol, son algunas de las características que identifican a la mayor parte de Latinoamérica (Santillana sl.6o․ 2008: 96).

\section{Guatemalay Honduras}

En los libros de Guatemala y Honduras de la editorial Santillana se observan también referencias a la catolicidad como folclore e historia colonial, pero se habla poco del presente, en el siguiente tenor:

Las instituciones religiosas normalmente están vinculadas con las iglesias de distintos cultos, como la católica, la evangélica, la mormona y la adventista, entre otras [...] Para muchas personas, además de la familia y la escuela, las iglesias son muy importantes, ya que en ellas encuentran el lugar ideal para expresar su fe religiosa (Santillana gt.5ํㅡ. 2009a: 74).

El respeto y aprecio a las diferencias se agota en la enunciación del derecho a la libertad de religión (Santillana hn. $6^{\circ}$ g. 2006: 17). En cambio, abundan referencias a la construcción de templos como hechos históricos o como riqueza cultural: "La Iglesia de Comayagua es un bello edificio colonial e histórico". "La fundación de la Catedral de Tegucigalpa es un hecho histórico de esta ciudad" (Santillana hn.2º. 2006:57, 60, 61).

Una de las tradiciones más reconocidas es el baile de los Diablitos. En este baile se representa la conversión de un pagano al cristianismo. Se celebra del 5 al 12 de febrero de cada año. Entre los personajes que intervienen en el baile están los moros y cristianos... La fiesta patronal de Comayagua se celebra del 8 al 12 de diciembre. Está dedicada a la Virgen de la Concepción (Santillana hn. $2^{\circ}$ g. 2006: 120).

La conquista y colonización de América tuvo una justificación para los españoles: difundir la fe católica. Los franciscanos fueron los primeros misioneros en llegar a América. Posteriormente llegaron otras congregaciones religiosas como los dominicos, agustinos, jesuitas, carmelitas y mercedarios. La Iglesia católica se constituyó en la institución más poderosa de la Colonia [...] Los frailes tuvieron la misión de enseñar el idioma español, la escritura y algunos oficios a los indígenas. Con el tiempo, los religiosos se ganaron la confianza de los indígenas y ejercieron gran influencia sobre ellos [...] Junto a los ritos y ceremonias católicas, persistían las costumbres y ritos indígenas. La unión de la religión indígena con la fe cristiana dio origen al sincretismo religioso. Durante la Colonia, los religiosos fundaron conventos, iglesias, escuelas, hospitales y universidades (Santillana hn. $5^{\circ}$ g. 2006: 103).

Recapitulando, las referencias a la religión católica, los templos católicos y las fiestas patronales son omnipresentes con mayor o menor énfasis en los libros de todos los países. Se habla de estos factores como patrimonio cultural, parte del folclor y tema de la historia colonial, para apuntalar una identidad nacional homogénea y monoétnica que gira en torno a una religión, una lengua y una cultura, justamente la narrativa decimonónica que el multiculturalismo y la escuela intercultural quieren exorcizar.

\section{Las religiones histórico-universales en los libros de sexto}

Los libros de sexto grado de Honduras, Guatemala y Nicaragua, dedicados a la geografía e historia universales, destacan las referencias al brahmanismo, budismo, islamismo, judaísmo y cristianismo. Vale la pena detenerse un poco en el espacio dedicado a cada una de estas religiones y al énfasis temático adoptado.

El libro de Santillana que usan los niños de Honduras apenas dedica un párrafo de tres o cuatro 
líneas al brahmanismo y el budismo en conjunto; en cambio, dedica sendas páginas a los siguientes siete tópicos entre los que predomina, sin lugar a dudas, el interés por los sucesos europeos o relacionados con él: el cristianismo y el Imperio romano, la Iglesia [católica] y la cultura medieval, el Islam, las cruzadas, el judaísmo, la Reforma y la Contrarreforma. Bajo el título "Época de persecuciones", se narra el nacimiento del cristianismo ocupándose del Imperio Romano, prácticamente sin referirse a los principios doctrinarios. ${ }^{9}$

En extensión similar, de una página, bajo el rótulo "Una religión con una fuerza militar", se narra el surgimiento y la expansión del Islam. En las primeras líneas se expresan los fundamentos básicos de su credo y el resto trata de su expansión política y militar. Llama la atención que, al considerar la prédica de Mahoma, se diga que, "según él", recibió la revelación de Alá. Parecería inaudito para la sensibilidad católica siquiera pensar en este giro, "según él”, para expresar que, según el propio Cristo, él es el hijo de Dios, pues indicaría cierta duda o incluso una descalificación. ${ }^{10}$

Ante tal amenaza, la Iglesia católica medieval respondió con las cruzadas y fue la artífice del nuevo orden, según se desprende del texto, en el que se identifican con claridad los intereses económicos y políticos de los grupos beneficiados con tales guerras. ${ }^{11}$

La sección dedicada al judaísmo lleva por título "La dispersión de un pueblo" y en ella, sin detenerse a explicar las creencias, se dedica a exponer el papel de esta religión en la historia europea. ${ }^{12}$

Al referirse al surgimiento de las Iglesias protestantes, explica el poder de la católica, el descontento con algunas de sus acciones, la protesta de Lutero en Alemania y sus consecuencias. El libro dedica la lección titulada "Conflictos religiosos" íntegramente al luteranismo, a excepción de tres líneas finales en las que menciona el calvinismo y el anglicanismo, aunque nada explica de las diferencias doctrinales entre las Iglesias reformadas y entre éstas y la católica. ${ }^{13}$

En el tema titulado "La reacción de los católicos", en cambio, se señalan los cambios o pasos que no alcanzó a dar el catolicismo en la llamada contrarreforma en relación con los protestantes. ${ }^{14}$
En fin, la unidad dedicada a la historia universal en el libro de sexto año editado por Santillana para las escuelas hondureñas menciona, casi de paso, la existencia de las religiones del mundo oriental o Lejano Oriente: brahmanismo, budismo, etcétera; de las nacidas en el Cercano Oriente, islamismo, judaísmo y cristianismo, se ocupa con mayor detenimiento, pero sólo como acontecimientos históricos importantes para Europa, sin dar explicaciones de los contrastes doctrinarios.

En la segunda unidad del mismo libro de Santillana, dedicada a la Geografía física y humana, están ausentes las referencias a las religiones; en cambio las toma en cuenta el libro, también de Honduras, editado por Ramiro Colindres y publicado por Graficentro Editores en 2005. En Estados Unidos, dice, predominan los protestantes, en Canadá y América Latina los católicos, en Europa los cristianos divididos en católicos, protestantes y ortodoxos a excepción de Albania en donde son mayoría los musulmanes (Graficentro hn.6ํ. 2005: 41, 49, 50).

De Asia, explica que "es la cuna de las principales religiones del mundo. El budismo predomina en Oriente; el hinduismo en la India; el Islam al oeste y sureste; el cristianismo, que nació en Palestina, está presente en la mayoría de los países asiáticos" (Graficentrohn.6ํㅜ․ 2005: 77). En África:

La mayoría de los habitantes de raza negra practican las religiones animistas o sea, creen que todos los seres materiales tienen alma y son vivientes. Los fenómenos naturales son interpretados como expresión buena o mala de las cosas que los producen. Los abisinios y descendientes de europeos, son cristianos. El mahometismo es la religión de la mayoría en los pueblos árabes, sudaneses y muchos negros (Graficentrohn.6‥ 2005: 105).

En Oceanía en general hay un predominio cristiano, católico y protestante, pero se practican las religiones bahai, hindú, musulmana, panteísta y animista (Graficentro hn.6 ${ }^{\circ}$. 2005: 130).

En el capítulo dedicado a la historia es más prolífica la presencia del tema religión, se ocupa de caracterizar 
las creencias, no sólo de enunciarlas, y esa es su cualidad y contraste con la pulcra, didáctica y dosificada edición de Santillana. Incluso en el capítulo de geografía, al referirse a África, como se lee en la cita anterior, informa del carácter central del animismo. Ciertamente el libro de Graficentro adolece del uso de terminología racial y poca sofisticación didáctica exhibida en la composición de la edición, de colores recargados, márgenes estrechos, textos muy amontonados y extensos, aunque agotado en una colección de fichas temáticas bien ordenadas. Sin embargo, permite a los alumnos informarse de en qué consiste la diversidad religiosa, más allá de las simples denominaciones. Repasa así las creencias de los pueblos antiguos de Mesopotamia, Egipto, Persia, China, India, Grecia y Roma (Graficentrohn.6ㅇ. 2005: 179, 183, 186, 189, 190-191, 202). El ejemplo de la India es insuperable para ver lo prolífico del tratamiento del tema, que en términos didácticos es poco eficiente para el aprendizaje, pero sin duda hace mayor justicia al conocimiento y aprecio de la diversidad. ${ }^{15}$

Sin duda es contrastante el tratamiento dado entre editoriales al tema de las religiones en el Lejano Oriente, en una ausente, en la otra presente con énfasis histórico además de doctrinario. En las religiones del Cercano Oriente - judaísmo, cristianismo e islamismo- el contraste, además de la mayor amplitud histórica, está en el énfasis doctrinario, incluso con citas bíblicas, ausente en la editorial Santillana. ${ }^{16}$

Este contraste se mantiene en los libros de otras editoriales frente a los de Santillana en Guatemala y Nicaragua, y a los de países como Honduras, que se ocupan en el sexto grado de la historia universal (Susaeta gt. $6^{0}$. 2003; Santillana gt. $6^{\circ}$. 2009a; San Jerónimo ni. $6^{\mathrm{O}}$. 2006; Santillana ni. $6^{\mathrm{O}}$. 2007). ${ }^{17}$

\section{Consideraciones finales}

Los libros de Ciencias Sociales de los países de Centroamérica tratan el tema de la diversidad religiosa apenas como enunciando su existencia, y no reflejan la importancia numérica del fenómeno, mucho menos los contrastes doctrinarios. En cambio, naturalizan la catolicidad mediante la invocación de templos, fiestas patronales y tradición como patrimonio cultural, parte del folclor y la historia, como característica de la identidad nacional, dominante, homogénea. Está ausente en ellos la visión multicultural que aboga por una escuela intercultural, en donde se respete, celebre y aprecie la diversidad.

En un artículo dedicado a la escritura de la historia y la interculturalidad contra la visión decimonónica del discurso monoétnico nacionalista, Elisa Cárdenas aboga por una reescritura de la historia desde una efectiva perspectiva intercultural, que no se agote en la enunciación de culturas a manera de un catálogo, "que hace de éstas compartimentos estancos, sino atendiendo a los lugares y formas de la interacción entre diferentes" (Cárdenas, 2013: 16-17). Lo mismo debe pedirse a los libros escolares respecto a la diversidad religiosa, ya que hasta ahora lo que hacen es naturalizar la religión católica, sólo nombran otras denominaciones cristianas y apenas mencionan algunas otras creencias al tratar sobre el presente. Cuando se ocupan de las Iglesias históricas y de religiones universales, lo hacen en términos de la historia antigua, no de la diversidad contemporánea de creencias, y lo hacen desde un destacado interés eurocéntrico y catolicéntrico por historiar los antecedentes de la homogénea identidad nacional.

En resumen, la puesta en boga de regímenes con principios democráticos, promotores de la conservación ambiental, el respeto de la diversidad cultural y los derechos humanos en los países de Centroamérica, no se refleja en los libros de texto utilizados en el área de Ciencias Sociales de la escuela primaria. Más bien traicionan tales principios, aunque algunos los invocan hasta la saciedad; reproducen los principios establecidos en los programas oficiales convirtiéndolos en estribillos de moda, conductas de fachada circunscritas a llanos discursos políticamente correctos en relación con el aprecio y respeto de la diversidad, la cual se agota en el simple listado de adscripciones religiosas principales y el repaso de la aparición histórica de las religiones universales, sin reflexión sobre los contrastes doctrinarios entre ellas, los conflictos contemporáneos en su nombre y la multiplicación de las denominaciones 
en el último medio siglo. En cambio, se presenta la catolicidad naturalizada como un hecho histórico, patrimonio cultural y folclor. Por tanto, la presentación de la diversidad religiosa en los libros escolares trabaja en dirección contraria a la convivencia intercultural y a la constitución de un patriotismo constitucional.

\section{Notas}

${ }^{1}$ Por ejemplo, en Costa Rica el número de iglesias pentecostales pasó de 215 a 1088 entre 1974 y 1985, con diferencias en el ritmo de crecimiento entre las siete provincias pero con presencia y expansión en todas (Valverde, 1990: 89).

${ }^{2}$ En Nicaragua, en 1963 el catolicismo representaba el 96\% del total; en cambio, el censo de 2005 reportó que la población católica descendió al 59\%, los sin religión aumentaron a $16 \%$ y el resto creció hasta representar el 25\% (ver: http://www.inide.gob.ni/).

${ }^{3}$ Enunfolleto, anunciadocomo versión popular del trabajo de Benjamín Cortés: "Introducción a las periodizaciones históricas del protestantismo nicaragüense" publicado en el libro Reforma y conquista. América Latina 500 años después, se lee: "Los primeros intentos de evangelización protestante fueron realizados por unos puritanos ingleses que se habían establecido en la isla Providencia, quienes además de organizar el intercambio comercial con la comunidad miskita de Cabo Gracias a Dios, a partir de 1633..." (CIEETS, 1989: 5).

${ }^{4}$ El país más católico es Costa Rica, con $71 \%$ de la población, el menos católico es Honduras con apenas $47 \%$. Los sin religión o que no respondieron, en el conjunto centroamericano, van de 6 a $16 \%$, y los adscritos a otras religiones del 2 al 4\%.

${ }^{5}$ En Panamá, las editoriales dan dinero a los maestros que solicitan sus libros a los alumnos. Los profesores sostienen que los textos están mal adaptados a partir de los colombianos. Los libros más vendidos son los de la Editorial Santillana y los de Susaeta Ediciones. Estos últimos son más sencillos, mejores, aunque igual de caros que los primeros. En promedio cada uno cuesta diez dólares, los maestros me dicen que en las escuelas de zonas empobrecidas ni siquiera se hace el intento de pedir a los padres de familia que los compren. Algunas escuelas tienen los libros de Santillana a partir de un financiamiento del PNUD, los niños los usan en el salón de clases y los dejan para la siguiente generación.

${ }^{6}$ Las referencias de los libros escolares se encabezan con el nombre de la editorial, seguido por las letras que en internet se utilizan para reconocer a los países — gt, sl, hn, ni, cr y pa, por Guatemala, El Salvador, Honduras, Nicaragua, Costa Rica y Panamá, respectivamente- y el grado escolar correspondiente. La intención es que se pueda identificar con agilidad y precisión la editorial, el país y el grado del texto citado. Es común que la autoría en los libros de texto escolar suela diluirse en largos listados de los integrantes de grandes equipos, incluso ocultarse dando primacía a los funcionarios o directores de dichos equipos editoriales. En los casos trabajados, sólo los textos de Nicaragua de la editorial Hispamer destacan la autoría de Jaime Incer y Germán Romero y, en los de Honduras editados por Graficentro, se da relevancia al editor Ramiro Colindres. Una reflexión sobre el profesorado, la escritura y la autoría, particularmente para el caso de México, pero ilustrativo para los países de Centroamérica puede verse en Rockwell (1992), en especial en las páginas 52 y 53.

${ }^{7}$ En este texto también hay una discontinuidad entre la comunidad que construye su historia y los habitantes que adquieren tradiciones y costumbres: el énfasis habría de estar en que los habitantes son la comunidad y también construyen, no adquieren algo externo simplemente.

${ }^{8}$ Los libros de Eduvisión enfatizan mucho los temas transversales de respeto, tolerancia y aprecio de la diversidad en la presentación de objetivos y competencias, unidad por unidad, pero sus contenidos no reflejan tal importancia, son demagógicos y descuidados a ese respecto. Además, no están estandarizados en su presentación de contenidos y número de unidades. Los de Santillana tienen mejor calidad en contenido, formación, formato, impresión y papel y sobre todo mayor congruencia con el plan de estudios y los conocimientos más avanzados, se organizan todos en cuatro unidades: Espacios geográficos, Acontecer histórico, Formación ciudadana 
y Mi carpeta. Esta última presenta materiales de trabajo para las tres unidades temáticas. Son libros que se editan en 2007, como los de la otra editorial, pero se presentan como "2a edición. Nuevos programas". Sin duda corresponden a los mismos planes de estudio oficiales.

9 "Roma toleraba las religiones de los pueblos dominados mientras no afectaran su seguridad. Se puede decir que el Imperio fue sincretista, es decir, que aceptaba diferentes creencias religiosas e incluso las hacía suyas". "En Palestina surgió un movimiento social y religioso que siglos más tarde tuvo gran repercusión en el imperio: el cristianismo. Del siglo I al III se dio un gran auge religioso dentro del imperio. El cristianismo aprovechó tal situación para expandirse hasta llegar a cubrir las principales ciudades y religiones del imperio [...] La estructura igualitaria de los cristianos, el rechazo del culto al emperador y a los dioses romanos, y su toma de distancia del circo, el teatro y otros elementos culturales, les granjeó el título de ateos y rebeldes frente al imperio. De forma progresiva, las persecuciones en su contra aumentaron [...] La primera persecución, ocurrida en $64 \mathrm{~d}$. de C., fue decretada por Nerón después de culparlos del incendio de Roma que él había iniciado. Domiciano decretó otra persecución en 93 d. de C. Durante los siglos II y III se suceden varios períodos de persecución seguidos de períodos de paz [...] Sin embargo, el movimiento cristiano seguía creciendo, sobre todo en los medios populares. También dentro de algunos filósofos e intelectuales de la época y el ejército romano [...] A finales del siglo III, el cristianismo estaba fuertemente arraigado en distintas regiones del imperio: Roma, el norte de África, Grecia, Egipto, Siria y Palestina. En el siglo IV, Constantino decidió permitir su práctica mediante el Edicto de Milán. Pronto el Emperador asumió el liderazgo en el Concilio de Nicea. En 392, el emperador Teodosio declaró que el cristianismo sería la religión oficial y única del imperio" (Santillana hn. $6^{\circ}$ g. 2006: 108).

10 "El Islam es una religión monoteísta que surgió en la península Arábiga durante el siglo VII. Se le conoce también como religión musulmana. Se basa en una doctrina sencilla, cuyos preceptos básicos se establecen en su libro sagrado, el Corán. Sus cinco pilares son la profesión de fe en Alá y su profeta Mahoma, la oración cinco veces al día, la limosna, el ayuno en el mes de Ramadán y la peregrinación a La Meca [...] Antes del surgimiento del Islam no había unidad en Arabia. Cada tribu tenía sus propios intereses y creencias. Los beduinos se dedicaban al pastoreo y los árabes al comercio. Solo existía en común la lengua árabe y un culto a la Piedra Negra del santuario de la Kaaba, situado en la ciudad de La Meca [...] A comienzos del siglo VII, Mahoma comenzó a predicar en La Meca las revelaciones que, según él, había recibido de Alá. La reacción en contra que provocó le obligó a huir a Medina en el año 622, viaje conocido como Hégira [...] En Medina fue respaldado por la población, y atacó La Meca en 623. Pronto recibió el apoyo de las tribus árabes, y a su muerte, en 632, ya había unificado toda la península. La idea de la Guerra Santa (Yihad) fue el motor de la expansión del Islam [...] Sus sucesores emprendieron rápidas conquistas fuera de Arabia. En 638 invaden Mesopotamia; en 642, el Imperio Persa; en 648, Egipto. Más tarde conquistan el valle del Indo hacía en este, y hacia el oeste el norte de África y la península Ibérica [...] En Francia fueron detenidos por el reino franco. Intentaron conquistar Constantinopla, pero no lo lograron. A partir de entonces se convirtieron en una continua amenaza militar y religiosa para Europa y el Imperio Romano de Oriente o Bizantino, que había sobrevivido a las invasiones bárbaras" (Santillana hn. $6^{\circ}$ g. 2006: 116).

11 "Durante la Alta Edad Media, los monjes evangelizaron las regiones de Europa que no eran cristianas. Con su valoración del trabajo manual colonizaron bosques, crearon terrenos de cultivo, desecaron pantanos y fundaron lugares de refugio en zonas fronterizas. Pronto los monasterios se constituyeron en centros económicos y culturales alrededor de los cuales surgieron algunas ciudades europeas importantes [...] La Iglesia fue la institución más influyente de la Edad Media. En esa época se consolidó como un gran poder, aliándose con las monarquías y acumulando numerosas posesiones y vasallos que trabajaban sus 
tierras". "La Iglesia y los monasterios dominaron la cultura. Los monjes rescataron los valores de la cultura antigua y se convirtieron en los forjadores de la nueva cultura medieval. Son ellos quienes copiaron y conservaron para la posteridad gran parte del saber de la antigüedad. Las primeras universidades se fundaron en la época medieval" (Santillana hn.6 g. 2006: 115). "El crecimiento económico motivó la expansión europea realizada mediante las Cruzadas entre el siglo XI y el XIII. Se trató de empresas militares y religiosas realizadas por algunos reyes cristianos y señores feudales europeos con el objetivo de rescatar los Santos Lugares en Palestina, que habían caído en manos de los musulmanes [...] Estuvieron motivadas por el fervor cristiano de la época, el espíritu caballeresco y guerrero de la nobleza feudal y las posibilidades de obtener el control de la zona estratégica que significaba Palestina [...] Hubo ocho cruzadas en total, que se desarrollaron entre los siglos XI y XIII. No tuvieron éxito duradero porque Palestina siguió en manos musulmanas. Sin embargo, tales expediciones profundizaron los vínculos comerciales y culturales entre Oriente y Occidente. La gran triunfadora fue la burguesía, que se fortaleció en Europa" (Santillana hn.6 g. 2006: 117).

12 "El judaísmo surgió en Palestina hace más de 3,000 años. Durante el helenismo, los judíos empezaron a dispersarse por las diferentes ciudades de Asia y Grecia. Durante el Imperio Romano continuaron este proceso y llegaron hasta la península Ibérica [...] Palestina era una provincia rebelde, donde constantemente surgían movimientos de carácter político-religioso que Roma reprimió, al extremo de llegar a destruir Jerusalén en el año 70 d. de C. Así se generó el proceso conocido como la diáspora judía». «De ahí que fuera fácil encontrar comunidades judías en la mayoría de ciudades importantes de Europa, Asia y Egipto. Su solidaridad de grupo y su habilidad para los negocios les trajo, en muchas oportunidades, el rechazo de sus vecinos [...] Durante la Edad Media los cristianos persiguieron a los judíos con frecuentes expulsiones, bautismos a la fuerza y matanzas. Las causas fueron: la Iglesia y los reinos cristianos buscaron consolidar y acrecentar su poder impulsando la unidad religiosa en sus dominios.
Para ello se aprovecharon del gran fervor religioso de la época medieval para incitar al pueblo contra 'los que crucificaron a Jesucristo'. Se les responsabilizó de la epidemia de peste negra, por ejemplo. Ante las restricciones legales y la amenaza de expulsión, los judíos que se enriquecían preferían acumular dinero en efectivo antes que comprar bienes inmuebles. Muchos se hicieron prestamistas y adquirieron fama de avariciosos, ya que durante la Edad Media era considerado un pecado el préstamo a interés que practicaban los judíos. Numerosos cristianos se endeudaron con alguno de ellos, e incitaron a la población a atacar a los judíos como una forma de acabar con sus deudas [...] Entre los siglos XI y XV, los judíos sufren numerosas matanzas y son expulsados de gran parte de Europa occidental. Los judíos españoles se distribuyeron por Grecia, Turquía, Palestina y el norte de África. Sus descendientes son los sefardíes, que en la actualidad aún conservan el viejo idioma castellano, también llamado ladino" (Santillana hn. $6^{\circ}$ g. 2006: 119).

13 "Durante la Edad Media, la Iglesia estuvo en el centro del poder y llegó a ser una gran potencia económica y política. Con el Renacimiento, el conflicto se hizo evidente: los reyes y comerciantes burgueses deseaban las tierras y posesiones de la Iglesia en los diferentes estados europeos y querían dejar de pagarle impuestos [...] Por otra parte, existía, entre muchos cristianos, el deseo de un cambio profundo en muchas de las estructuras de la Iglesia. En toda Europa se empezaron a levantar voces de protesta contra la Iglesia [...] En este contexto, la Iglesia de Roma decretó la venta de indulgencias para financiar la construcción de una basílica. El monje alemán Martin Lutero protestó contra Roma e hizo público, en 1517, un documento con 95 tesis en las que exponía una crítica profunda a la Iglesia [...] Sus tesis tuvieron una rápida difusión en Alemania, y pronto la reacción de los príncipes y el pueblo fue a su favor. El movimiento de protesta tomó un carácter político, y Lutero se convirtió en portador del descontento alemán y líder de un movimiento de grandes proporciones [...] La Iglesia de Roma no valoró el significado de este movimiento. Decidió llamar al orden a Lutero sin escuchar sus planteamientos. Esto 
fue aprovechado por los príncipes alemanes, quienes despojaron a la Iglesia de las posesiones que tenía en terreno alemán y se negaron a seguir pagando los impuestos. Tras un período de guerra, los nobles alemanes triunfaron. Con esto quedaba decretada la independencia de los alemanes respecto de Roma, y la reforma religiosa siguió su rumbo. Había nacido el luteranismo [...] Este fenómeno político-religioso se generalizó y aparecieron reformadores en Suiza, con Zuinglio, y en Francia, con Calvino. Surgen así otras ramas protestantes: los calvinistas en Francia y Suiza; y los anglicanos en Inglaterra con Enrique VIII" (Santillana hn.6 $6^{\circ}$. 2006: 128).

14 "Las voces de protestas contra la situación de la Iglesia romana se habían hecho presentes a lo largo de todo el siglo XV. Con la ruptura en los protestantes en el siglo XVI, la urgencia de una reforma en el interior de la Iglesia católica se hizo evidente, aunque la reacción fue lenta [...] En 1535, 17 años después de la crisis de Lutero, el papa Pablo III convocó al Concilio de Trento. Con ello se pretendía unir la cristiandad y discutir los aspectos doctrinales y disciplinarios que estaban en debate con la división de los protestantes. Sin embargo, el proceso fue demasiado lento. El concilio comenzó 10 años más tarde y terminó en 1563. Para entonces, la división entre protestantes y católicos estaba consumada". "El concilio no logró asimilar medidas importantes que se habían conseguido con los protestantes. Entre ellas sobresalía la lectura de la Biblia por parte del pueblo, la importancia de los laicos y la práctica de la liturgia en las lenguas locales de cada región. La liturgia continuó en latín, lengua que la gente ya no entendía" (Santillana hn. $6^{\circ}$ g. 2006: 129).

15 "El vedismo fue la primera de las teorías religiosas en la India y está recopilada en los libros de los Vedas, escritos en sánscrito. Los libros son cuatro: Rig-Veda, libro de himnos religiosos; Sama-Veda, Yapur-Veda y AtharvaVeda, que constituyen fuentes de conocimiento de la Literatura, la Ciencia y el Derecho de ese pueblo. Estas creencias se basaban en un politeísmo primitivo con representaciones de las fuerzas naturales. Después del establecimiento de los arios, se impone el brahmanismo, por la influencia de los brahmanes. Éstos adoraban a
Brahma, dios creador, y junto a él estaban los espíritus de Shiva, el destructor, y de Visnú, él preservador, dioses estos de la época védica. La casta de los brahmanes era la única que podía practicar el ritual. El brahmanismo cree en la transmisión de las almas, es decir, cada alma después de la muerte puede reencarnar en un ser vivo. Puede ascender o descender en el sistema de castas o reencarnar en un animal, todo dependiendo de la clase de vida que hubiese llevado la persona. Fomentaba la creencia de que la buena conducta del individuo en su propia casta era la condición indispensable para reencarnar en una casta superior" (Graficentro hn.6\% 2005: 190). "De hecho, ese tipo de carencia lo que hacía era preservar el sistema y la inmovilidad social, así los brahmanes conservaban sus privilegios y las demás castas se mantenían inmóviles esperando su ascenso en una próxima reencarnación. Fruto del descontento con las creencias brahmánicas y su división en castas, surge en la India una nueva religión: el budismo, derivado de Buda o Budha. Hacia el año 560 a. de J. C., Gautama Buda, un miembro de la casta de los chatrias, introduce cambios tan sustanciales en la religión hindú que a su doctrina se le llama budismo y tendrá una personalidad propia. Buda cambia el concepto de reencarnación. Su doctrina cree en la posibilidad de la perfección del hombre sin importar su casta u origen. La reencarnación dependerá únicamente del grado de moralidad y ascetismo, y no del cumplimiento de deberes de casta. La individualidad va reencarnando hasta purificarse y llegar al Nirvana o la identificación con lo Supremo. El budismo supone una crítica al sistema de castas, y por ende, tuvo mayor aceptación entre las clases inferiores. Su máxima expansión ocurre durante el imperio Maurya. En el siglo I se expande por China y el sudeste de Asia. Sin embargo, esta religión, en el año 700 d. de J. C., fue desplazada por el hinduismo" (Graficentro hn.6ㅇ. 2005: 190-191). "El hinduismo se basa en la creencia en un Dios, Brahma, al que se le añadieron otros dioses. Acepta la metempsícosis o transmigración de las almas y utiliza la ascesis para superar esta situación. Esta religión va a tener aceptación entre los brahmanes porque les concede un importante papel purificador. Budistas e hinduistas llegaron a tener grandes enfrentamientos, 
triunfando estos últimos. En el siglo XII penetró el islamismo en la India" (Graficentro hn.6ํ. 2005: 191).

16 "Israel, desde sus orígenes, trató de mantener su unidad a través de una religión monoteísta. Los israelitas tenían la esperanza de un Mesías salvador del pueblo, de un caudillo que vendría a liberarlos de la opresión que sufrían bajo el decadente Imperio Romano, como sucedió con Moisés, que los había liberado de la esclavitud del Faraón de Egipto. En ese contexto nació Jesucristo en Belén (Lucas 2, 1.6), un pequeño pueblo de Judea al Sur de Palestina. Él afirmaba ser el Hijo de Dios; su misión en el mundo era dar la vida para redimir a la humanidad. La doctrina de Cristo está recopilada en el Nuevo Testamento, segunda parte de la Biblia. El nacimiento de Jesús es un hecho histórico que revolucionó la historia de la humanidad, hasta el punto de establecerse la cronología en dos etapas; antes de Cristo (a. de J. C.) y después de Cristo (d. de J. C.). Jesucristo predicó la igualdad de los hombres y las mujeres ante Dios, por ser hijos de un mismo Dios Creador y Padre que perdona y ama a toda la Humanidad; 'De tal manera amó Dios al mundo que dio a su Hijo Unigénito para que todo aquel que crea en Él no perezca, sino que tenga vida eterna' (Juan 3 , 15-16). Combatió la práctica de adoración al emperador, "Dad al César lo que es del César y a Dios lo que Dios" (Lucas 20,25). Con esta expresión, quería significar que al César se le debían pagar los tributos y a Dios darle adoración" (Graficentro hn.6\%. 2005: 213). "Mahoma predicó en Arabia una religión nueva, la islámica (palabra que quiere decir sumisión) o musulmana (resignado a la voluntad de Dios), basada en principios judíos y cristianos y en algunas tradiciones árabes [...] Los dogmas fundamentales de esta religión son: creencia en un solo dios llamado Alá, ser supremo, Dios personal, Creador del Universo, omnipotente y misericordioso; y creencia en que la paz y el sosiego interior dependen de la sumisión y de la resignación a la voluntad de dios. Decía Mahoma: 'no digas quiero, sino: así lo quiere Dios' [...] La doctrina predicada por Mahoma se concentra en la ayuda al débil, en la limosna, en la oración cinco veces al día, en el ayuno en el mes de Ramadán y en la peregrinando a La Meca por lo menos una vez en la vida. Establece la guerra como algo que así quiere dios: 'Combatid a nuestros enemigos en la guerra encendida por la defensa de la religión... si os atacaran durante los meses sagrados y en los lugares santos, hacedles sufrir la pena del Talión, violad las leyes que en sus códigos equivalen a las que ellos os han violado...' La doctrina de Mahoma está enunciada en El Corán, libro sagrado de los mahometanos. Contiene en 114 suras o capítulos las normas religiosas, sociales y políticas que rigen la vida de un creyente" (Graficentro hn.6‥ 2005: 219).

${ }^{17}$ Los libros de los primeros seis grados, primero y segundo ciclo, de la educación básica en El Salvador, Costa Rica y Panamá no se ocupan de la historia universal, se detienen en la del continente americano.

\section{Referencias bibliográficas}

Apple, Michael W. (1986), Maestros y textos. Una economía política de las relaciones de clase y sexo en educación. Madrid: Paidós.

Carbone, Graciela M. (2003), Libros escolares una introducción a su análisis y evaluación. Buenos Aires: Fondo de Cultura Económica.

Cárdenas-Ayala, Elisa (2013), "Historia nacional e interculturalidad: apuntes chiapanecos". En Liminar. Estudios Sociales y Humanísticos, vol. XI, núm. 1, pp. 13-28.

CIEETS (1989), Caminando. Breve historia de la Iglesia evangélica nicaragüense. Managua: Centro Intereclesial de Estudios Teológicos y Sociales.

Escolano, Benito Agustín (1997), "Introducción”. En Agustín Escolano Benito (dir.), Historia ilustrada del libro escolar en España del Antiguo Régimen a la Segunda República. Madrid: Fundación Germán Sánchez Ruipérez, pp. 13-17.

Ferro, Marc (2007), Cómo se cuenta la historia a los niños de todo el mundo. México: Fondo de Cultura Económica.

Rockwell, Elsie (1992), "Los usos magisteriales de la lengua escrita”. En Nueva Antropología, vol. XII, núm. 42, pp. 43-55.

Rosales, José María (2000a), “La educación de laidentidad cívica: sobre las relaciones entre nacionalismo y patriotismo". En José Rubio Carracedo, José María Rosales y Manuel Toscano Méndez (coord.), 
Ciudadanía, nacionalismo y derechos humanos. Madrid: Trotta, pp. 117-132.

Rosales, José María (2000b), “Sobre la idea de patriotismo constitucional”, En José Rubio Carracedo, José María Rosales y Manuel Toscano Méndez, Ciudadanía nacionalismoy derechos humanos. Madrid: Trotta, pp. 133-150.

Tilleman, Benjamin F. (2004), La influencia morava en el paisaje de la Mosquitia hondureña. Tegucigalpa: Guaymuras.

Valverde, Jaime (1990), Las sectas en Costa Rica. Pentecostalismo y conflicto social. San José: Departamento Ecuménico de Investigaciones.

\section{Textos escolares citados}

Eduvisión cr.l $1^{0}$ g. (2007), Nuevos destinos de Estudios sociales l. San José.

Eduvisión cr.2ํ. (2007), Nuevos destinos de Estudios sociales 2. San José.

Eduvisión cr.3ํg. (2007), Nuevos destinos de Estudios sociales 3. San José.

Eduvisión cr.4ํg. (2007), Nuevos destinos de Estudios sociales 4. San José.

Graficentro hn. $6^{\circ} \mathrm{g}$. (2005), Ciencias sociales 6 grado. Tegucigalpa.

Hispamer ni.5ํㅡ. (2007), 5to.grado. Estudios sociales. Managua.

Hispamer ni.6ㅇ․ (2007), 6to.grado. Estudios sociales. Managua.

Mined sl. $1^{\circ}$ g. (2008), Estudios sociales 1. San Salvador. Mined sl. $4^{\circ}$ g. (2009), Estudios sociales 4. San Salvador.
Mined sl.6ํ․ (2009), Estudios sociales 6. San Salvador.

San Jerónimo ni. $3^{\circ} \mathrm{g}$. (2006), Estudios sociales 3‥ Grado. Managua.

San Jerónimo ni. $4^{\circ} \mathrm{g}$. (2006), Estudios sociales 4․ Grado. Managua.

San Jerónimo ni. $5^{\circ}$ g. (2006), Estudios sociales 5. Grado. Managua.

San Jerónimo ni.6º. (2006), Estudios sociales 6o. Grado. Managua.

Santillana gt.5ํㅡ. (2009a), Enlaces 5. Ciencias sociales. Guatemala.

Santillana gt.6ำ. (2009a), Enlaces 6. Ciencias sociales. Guatemala.

Santillana hn. $2^{\circ}$ g. (2006), Ciencias sociales 2. Aventuras. Tegucigalpa.

Santillana hn. $5^{\circ}$ g. (2006), Ciencias sociales 5. Aventuras. Tegucigalpa.

Santillana hn. $6^{\circ}$ g. (2006), Ciencias sociales 6. Aventuras Tegucigalpa.

Santillana ni. $6^{\circ}$ g. (2007), Estudios sociales 6. San José. Santillana pa.l@g. (2006), Ciencias sociales l. Panamá. Santillana pa. $2^{\circ}$ g. (2006), Ciencias sociales 2. Panamá. Santillana pa.3ํg. (2006), Ciencias sociales 3. Panamá. Santillana pa.4ํ․ (2006), Ciencias sociales 4. Panamá. Santillana pa.5g. (2006), Ciencias sociales 5. Panamá. Santillana pa. $6^{\circ} \mathrm{g}$. (2006), Ciencias sociales 6. Panamá. Santillana sl. $3^{\circ}$ g. (2008), Estudios sociales 3. San Salvador. Santillana sl.5ำ. (2007), Estudios sociales 5. San Salvador. Santillana sl. $6^{\circ} \mathrm{g}$. (2008), Estudios sociales 6. San Salvador. Susaeta gt. $6^{\circ} \mathrm{g}$. (2003), Ciencias sociales y formación ciudadana 6. Guatemala. 
Cuadro 1. Población de los países de Centroamérica según adscripción religiosa, 2010

\begin{tabular}{|c|c|c|c|c|c|c|c|}
\hline \multirow[b]{2}{*}{ País } & \multirow{2}{*}{$\begin{array}{l}\text { Población } \\
\text { Total }\end{array}$} & \multirow[b]{2}{*}{ Denominaciones } & \multirow{2}{*}{$\begin{array}{l}\text { Iglesias } \\
\text { locales }\end{array}$} & \multicolumn{4}{|c|}{ Población según adscripción religiosa (\%) } \\
\hline & & & & Católica & $\begin{array}{l}\text { Protestante } \\
\text { o evangélica }\end{array}$ & Otras & $\begin{array}{l}\text { Sin religión, } \\
\text { sin respuesta }\end{array}$ \\
\hline Guatemala & 14361666 & 236 & 26530 & 57 & 31 & 2 & 10 \\
\hline El Salvador & 7440662 & 84 & 7700 & 50 & 38 & 3 & 9 \\
\hline Honduras & 8045990 & 113 & 13247 & 47 & 36 & 3 & 14 \\
\hline Nicaragua & 5815524 & & 7414 & 58 & 23 & 3 & 16 \\
\hline Costa Rica & 4563538 & 232 & 4871 & 71 & 20 & 2 & 7 \\
\hline Panamá & 3405813 & 56 & 3102 & 66 & 24 & 4 & 6 \\
\hline
\end{tabular}

Fuente: Prolades 2010. Disponible en http://www.prolades.com.historiografia/ 